\title{
Clinical and economic consequences of vancomycin and fidaxomicin for the treatment of Clostridium difficile infection in Canada
}

\author{
Monika Wagner PhD, Louis Lavoie PhD, Mireille Goetghebeur PhD
}

\begin{abstract}
M Wagner, L Lavoie, M Goetghebeur. Clinical and economic consequences of vancomycin and fidaxomicin for the treatment of Clostridium difficile infection in Canada. Can J Infect Dis Med Microbiol 2014;25(2):87-94.
\end{abstract}

BACKGROUND: Clostridium difficile infection (CDI) represents a public health problem with increasing incidence and severity.

OBJECTIVE: To evaluate the clinical and economic consequences of vancomycin compared with fidaxomicin in the treatment of CDI from the Canadian health care system perspective.

METHODS: A decision-tree model was developed to compare vancomycin and fidaxomicin for the treatment of severe CDI. The model assumed identical initial cure rates and included first recurrent episodes of CDI (base case). Treatment of patients presenting with recurrent CDI was examined as an alternative analysis. Costs included were for study medication, physician services and hospitalization. Cost effectiveness was measured as incremental cost per recurrence avoided. Sensitivity analyses of key input parameters were performed.

RESULTS: In a cohort of 1000 patients with an initial episode of severe CDI, treatment with fidaxomicin led to 137 fewer recurrences at an incremental cost of $\$ 1.81$ million, resulting in an incremental cost of $\$ 13,202$ per recurrence avoided. Among 1000 patients with recurrent CDI, 113 second recurrences were avoided at an incremental cost of $\$ 18,190$ per second recurrence avoided. Incremental costs per recurrence avoided increased with increasing proportion of cases caused by the NAP1/B1/027 strain. Results were sensitive to variations in recurrence rates and treatment duration but were robust to variations in other parameters.

CONCLUSIONS: The use of fidaxomicin is associated with a cost increase for the Canadian health care system. Clinical benefits of fidaxomicin compared with vancomycin depend on the proportion of cases caused by the NAP1/B1/027 strain in patients with severe CDI.

Key Words: Clostridium difficile; Cost effectiveness; Fidaxomicin; Recurrence; Vancomycin

$\mathrm{C}$ lostridium difficile infection (CDI) represents an important public health problem in both acute- and chronic-care facilities (1). CDI is involved in a significant proportion of cases of antibioticinduced diarrhea and can lead to severe outcomes such as pseudomembranous colitis and toxic megacolon (2). The occurrence of CDI has increased in the past two decades, with localized outbreaks of increased severity (especially in North America [including Quebec]) occurring in conjunction with the emergence of the more virulent NAP1/ B1/027 strain (3-8). During an outbreak in Quebec in 2004, Loo et al (3) estimated the incidence of nosocomial CDI to be 22.5 cases per 1000 admissions and the attributable mortality to be $6.9 \%$ per case. The Canadian Nosocomial Infection Surveillance Program Study (9) reported an incidence of 4.6 health care-associated CDI cases per 1000 hospital admissions and an attributable mortality rate of $5.7 \%$

\author{
Les conséquences cliniques et économiques de la \\ vancomycine et de la fidaxomicine pour traiter \\ l'infection à Clostridium difficile au Canada
}

HISTORIQUE : L'infection à Clostridium difficile (ICD) est un problème de santé publique à l'incidence et à la gravité croissantes.

OBJECTIF : Évaluer les conséquences cliniques et économiques de la vancomycine par rapport à la fidaxomicine pour traiter l'ICD dans le système de santé canadien.

MÉTHODOLOGIE : Les chercheurs ont élaboré un modèle d'arbre décisionnel pour comparer la vancomycine et la fidaxomicine dans le traitement des graves ICD. Selon ce modèle, le taux de guérison initial était identique et incluait les premiers épisodes récurrents d'ICD (cas de référence). L'autre méthode d'analyse examinée était le traitement des patients atteints d'ICD. Les coûts inclus étaient ceux du médicament à l'étude, des services des médecins et de l'hospitalisation. Les chercheurs ont mesuré l'efficacité des coûts sous forme de coût incrémentiel par récurrence évitée. Ils ont effectué les analyses de sensibilité des principaux paramètres d'entrée.

RÉSULTATS : Dans une cohorte de 1000 patients ayant eu un épisode initial de grave ICD, le traitement à la fidaxomicine suscitait 137 récurrences de moins à un coût incrémentiel de 1,81 million de dollars, pour un coût incrémentiel de 13202 \$ par récurrence évitée. Chez 1000 patients ayant eu une ICD récurrente, 113 deuxièmes récurrences ont été évitées, à un coût incrémentiel de 18190 \$ par deuxième récurrence évitée. Les coûts incrémentiels par récurrence évitée grimpaient proportionnellement à l'augmentation de la proportion des cas causés par la souche NAP1/B1/027. Les résultats étaient sensibles aux variations des taux de récurrence et de la durée de traitement, mais robustes aux variations des autres paramètres.

CONCLUSIONS : L'utilisation de fidaxomicine s'associe à une augmentation des coûts dans le système de santé canadien. Les avantages cliniques de la fidaxomicine par rapport à la vancomycine dépendent de la proportion de cas causés par la souche NAP1/B1/027 chez les patients atteints d'une grave ICD.

per case across Canada in early 2005. Corresponding figures were significantly higher for Quebec, with 12.8 cases per 1000 admissions and a reported mortality rate of $14.9 \%$ (9).

The rising incidence of CDI and the increasing proportion of more severe cases in Quebec during the period from 1991 to $2004(10,11)$ led to an increased economic burden associated with this disease. Nevertheless, data regarding the economic burden of CDI in a Canadian context are scarce $(1,12)$. In 2002, a Canadian cross-sectional study reported a minimum cost (antibiotic treatment and hospital stay only) of $\$ 128,200$ per hospital for an average of 10 readmissions for nosocomial C difficile-associated diarrhea (13). Based on a systematic literature review, the annual attributable health care costs of CDI in the United States were estimated to range from $\$ 433$ million to $\$ 797$ million per year (in 2008 \$USD) (12). Similar data are not available for Canada. 
TABLE 1

Model input parameters: Transition probabilities

\begin{tabular}{|c|c|c|}
\hline Parameter & Value $(95 \% \mathrm{Cl}$ range in $\mathrm{SA})$ & References, assumptions \\
\hline \multicolumn{3}{|l|}{ Initial cure rates } \\
\hline Severe disease (base case) & 0.813 & Louie et al (20), 2011; Cornely et al (21), 2012; Cornely et al (30), 2012 \\
\hline Patients with recurrent CDI (subgroup) & 0.926 & (M-ITT analysis); assumed to be the same in both treatment arms \\
\hline \multicolumn{3}{|l|}{ Analysis according to strain type } \\
\hline NAP1/B1/027 & 0.813 & \\
\hline Non-NAP1/B1/027 & 0.912 & \\
\hline \multicolumn{3}{|l|}{ Recurrence rates } \\
\hline \multicolumn{3}{|l|}{ Severe disease (base case) } \\
\hline Vancomycin & $0.283(0.211-0.354)$ & Louie et al (20), 2011; Cornely et al (21), 2012 (M-ITT analysis) \\
\hline Fidaxomicin & $0.114(0.062-0.167)$ & \\
\hline \multicolumn{3}{|l|}{ Patients with recurrent CDI (subgroup) } \\
\hline Vancomycin & $0.323(0.222-0.428)$ & Cornely et al (30), 2012 (M-ITT analysis) \\
\hline Fidaxomicin & $0.203(0.114-0.291)$ & \\
\hline \multicolumn{3}{|c|}{ NAP1/B1/027 (analysis according to strain type) } \\
\hline Vancomycin & $0.282(0.201-0.364)$ & Louie et al (20), 2011; Cornely et al (21), 2012 (M-ITT analysis) \\
\hline Fidaxomicin & $0.248(0.168-0.327)$ & \\
\hline \multicolumn{3}{|c|}{ Non-NAP1/B1/027 (analysis according to strain type) } \\
\hline Vancomycin & $0.278(0.219-0.336)$ & Louie et al (20), 2011; Cornely et al (21), 2012 (M-ITT analysis) \\
\hline Fidaxomicin & $0.097(0.059-0.135)$ & \\
\hline
\end{tabular}

CDI Clostridium difficile infection; M-ITT Modified intention-to-treat; SA Sensitivity analysis

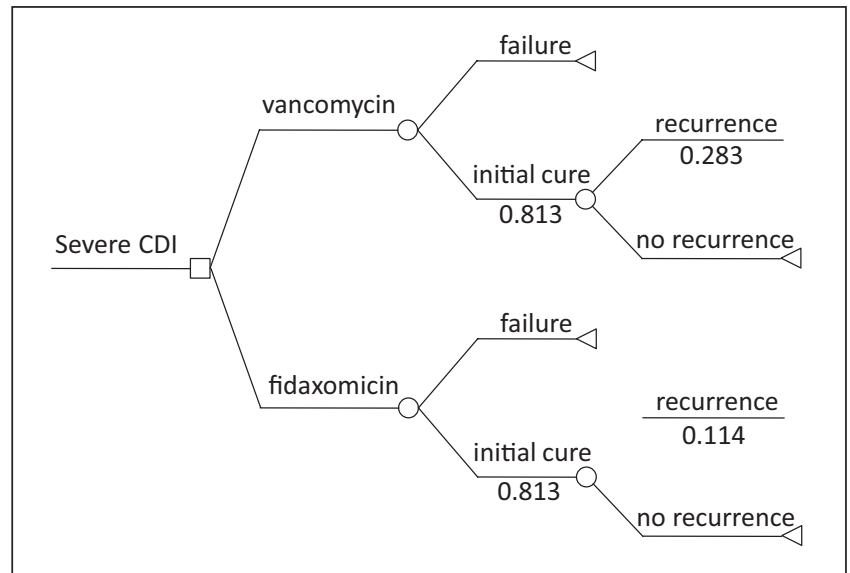

Figure 1) Decision-tree diagram for the treatment of patients with Clostridium difficile infection (CDI). Numbers are transition probabilities for patients with severe disease (base case)

According to current clinical practice guidelines for CDI in adults, metronidazole is the preferred treatment for mild to moderate CDI, whereas vancomycin is indicated for severe disease (14-16). A combination of vancomycin and metronidazole administered orally and intravenously, respectively, is the preferred treatment for severe, complicated CDI $(15,16)$. Recurrence of infection from the original strain (relapse) or from another strain (reinfection) remains an important issue, with $20 \%$ to $35 \%$ of patients with a first episode of C difficileassociated diarrhea experiencing at least one recurrence after the end of the initial standard therapy (vancomycin or metronidazole) $(17,18)$. Guidelines recommend the same regimen for the treatment of a first recurrence as for the initial episode (14-16).

In a recent review of the comparative efficacy of $\mathrm{C}$ difficile treatments, Drekonja et al (19) concluded that metronidazole, vancomycin and the new macrocyclic antibiotic fidaxomicin are similarly effective for initial cure of CDI in patients with diseases of variable severity. The review included the recent noninferiority trial conducted in Canada and the United States comparing fidaxomicin with vancomycin in CDI patients, which showed similar initial clinical cure rates $(88.2 \%$ versus $85.8 \%$, respectively) in the modified intention-to-treat population $(n=596)$ but fewer recurrences for fidaxomicin compared with vancomycin overall $(15.4 \%$ versus $25.3 \%$, respectively) and for patients infected with non-NAP1/B1/027 strains (10.3\% versus $28.1 \%$, respectively) (20). A second noninferiority clinical trial conducted in Europe and North America comparing fidaxomicin and vancomycin for treatment of patients with CDI was published after this review and reported similar results in the modified intention-to-treat population $(\mathrm{n}=509)(21)$. A meta-analysis of the two trials recently reported that fidaxomicin reduced by $40 \%$ a composite end-point of persistent diarrhea, recurrence or death during a 40-day follow-up (22). Although leading to fewer recurrences, fidaxomicin treatment is more expensive than treatment with vancomycin (19) and its cost utility from the perspective of a third-party payer in the United States has been recently estimated to be US\$67,576 per quality-adjusted life year (23).

The significant burden of CDI and the availability of a new treatment prompted us to evaluate the clinical and economic consequences of using vancomycin compared with fidaxomicin in the treatment of patients with CDI in the Canadian context from the perspective of the publicly funded health care system.

Model design

\section{METHODS}

A decision-tree model was developed in Excel 2007 (Microsoft Corporation, USA) to compare vancomycin and fidaxomicin for the treatment of patients with severe CDI (Figure 1). The treatment regimens compared were vancomycin (Vancocin) $125 \mathrm{mg}$ every $6 \mathrm{~h}$ for 10 days and fidaxomicin (Dificid; Optimer Pharmaceuticals Canada Inc, Canada) $200 \mathrm{mg}$ every $12 \mathrm{~h}$ for 10 days, as used in the comparative clinical trials $(20,21)$. Model transition probabilities are presented in Table 1. It was assumed that initial cure rates were identical in the two treatment arms because of the noninferiority reported in the trials $(20,21)$. After initial cure, the analysis included only the first recurrent episode of CDI, for which comparative rates following vancomycin and fidaxomicin in severe CDI patients were available $(20,21)$. Transition probabilities of initial cure and recurrence rates were calculated as the weighted average of rates from the two 
TABLE 2

Model input parameters: Resource utilization

\begin{tabular}{|c|c|c|}
\hline Parameter & $\begin{array}{l}\text { Type and quantity per patient using } \\
\text { resource (range in SA) }\end{array}$ & References, assumptions \\
\hline \multicolumn{3}{|l|}{ Medication } \\
\hline Vancomycin & $4 \times 125 \mathrm{mg}$ for $10(6-14)$ days & \multirow{2}{*}{$\begin{array}{l}\text { Louie et al (20), 2011; the same for recurrent episodes and initial } \\
\text { episode (Cohen et al [15], 2010) }\end{array}$} \\
\hline Fidaxomicin & $2 \times 200 \mathrm{mg}$ for $10(6-14)$ days & \\
\hline Proportion of initial episodes treated in hospital, \% & 63.8 & $\begin{array}{l}\text { Louie et al (20), } 2011 \text { and Cornely et al (21), 2012; assumed to } \\
\text { be the same in both treatment arms }\end{array}$ \\
\hline \multirow[t]{3}{*}{$\begin{array}{l}\text { Proportion of patients hospitalized for } \\
\text { recurrence }\end{array}$} & \multirow[t]{3}{*}{$0.193(0.110-0.276)$} & $\begin{array}{l}\text { Base: percent hospitalized within } 60 \text { days of recurrence }(62 \% \text {; } \\
\text { Pepin et al [24], 2006) multiplied by the proportion hospitalized } \\
\text { with primary CDI diagnosis (31\%; O'Brien et al [25], 2007) }\end{array}$ \\
\hline & & $\begin{array}{l}\text { Low: percent with complications (11\%; Pepin et al [24], 2006, } \\
\text { represents }-43 \% \text { of base value) }\end{array}$ \\
\hline & & High: $+43 \%$ of base value \\
\hline Inpatient (medical) physician services & $\begin{array}{l}\text { One consultation with GE or ID specialist, } \\
\text { and } 2(1-3) \text { additional assessments by GE } \\
\text { or ID specialist }\end{array}$ & Expert opinion \\
\hline \multicolumn{3}{|l|}{ Proportion of patients undergoing colectomy, \% } \\
\hline Initial episode & $3.84(1.5-4.0)$ & Pepin et al (7), 2007 \\
\hline Recurrent episodes & 0.65 & Pepin et al (24), 2006 \\
\hline Colectomy physician services & $\begin{array}{l}\text { One surgery (includes surgeon, } \\
\text { anesthesiologist and assistant) }\end{array}$ & Perras et al (26), 2011 \\
\hline Outpatient physician services & \multicolumn{2}{|c|}{ One limited consultation with family physician Perras et al (26), 2011} \\
\hline
\end{tabular}

GE Gastroenterologist; ID Infectious diseases; SA Sensitivity analysis

comparative clinical trials and are shown in Table 1. For recurrence rates, 95\% CIs were calculated using the following equation:

$$
p \pm 1.96 \times \sqrt{\frac{1}{n} p(1-p)}
$$

in which $p$ is the weighted average recurrence rate and $n$ is the total number of observations (patients).

The incremental cost per recurrence avoided was used as the measure of cost effectiveness. Recurrence was defined as reappearance of $>3$ diarrheal stools in $24 \mathrm{~h}$ within 28 days after the final dose of study medication; C difficile toxin A or B, or both, in stool samples; and a need for retreatment for CDI $(20,21)$. It was assumed that the episode of recurrence was treated using the same medication regimen as the initial episode, as recommended in clinical guidelines (14-16). The proportion of patients hospitalized for recurrence of CDI was derived from two studies. One study reported that $62 \%$ of patients experiencing a first episode of CDI were hospitalized within 60 days of recurrence (without providing the reason for hospitalization) (24). A second study reported that, among patients who were rehospitalized after an initial episode of CDI, $31 \%$ received a primary diagnosis of CDI (25). These two proportions were multiplied to estimate that $19.3 \%$ of patients were hospitalized with recurrence of CDI. The time horizon of the analysis was approximately two months after onset of the initial episode, which corresponds to the time over which the occurrence of the first recurrence was followed in the two clinical trials $(20,21)$.

\section{Patient population}

The target population of the model were patients with severe CDI as defined by clinical guidelines (ie, patients with a white blood cell count $15 \times 10^{9}$ cells/L or a serum creatinine level $\geq 1.5$ times the premorbid level [15]). This definition approximates the population defined as severe in the clinical trials comparing fidaxomicin with vancomycin (Louie et al [20] and Cornely et al [21]), which included patients with $\geq 10$ unformed bowel movements per day or with body temperature $>38.5^{\circ} \mathrm{C}$, respectively, as additional possible inclusion criteria $(20,21)$.

Resource utilization and costs

In accordance with the health care system perspective of the present analysis, the model included direct treatment costs, ie, study medication, physician services and hospitalization. Resource utilization and unit costs are listed in Tables 2 and 3, respectively. Resource utilization was based on the Louie et al (20) and Cornely et al (21) studies and on published Canadian sources $(7,24,26)$. Medication was assumed to be the same for the recurrent and initial episodes. The proportion of inpatients in the population entering the model was the same for both the fidaxomicin and vancomycin treatment arms, similar to the two clinical trials, and was estimated as the average of proportions reported in these trials $(20,21)$. It was assumed that one medical consultation and two additional assessments by a gastroenterologist or an infectious disease specialist were required for each patient hospitalized for CDI. The proportion of patients who underwent a colectomy during the initial episode of CDI was derived from a study involving 266 patients in Quebec with severe CDI defined by either leukocyte count or creatinine level (7). The proportion of patients who had a colectomy during the recurrent episode was derived from the number of colectomies among the patients $(n=463)$ who had a first recurrence of $\mathrm{C}$ difficile-associated disease in another study from the same research group (24).

The fidaxomicin acquisition cost was based on the value cited in the Common Drug Review of fidaxomicin by the Canadian Agency for Drugs and Technologies in Health (27). The costs of inpatient and outpatient physician consultations and assessments were obtained from the Ontario Schedule for Physician Services (28), and the cost for colectomy was obtained from a report of the Canadian Agency for Drugs and Technologies in Health (26). The hospital cost of an acute stay for enterocolitis (referred as the most responsible diagnosis in this database) was obtained from the Ontario Case Costing Initiative (29).

\section{Subgroup analysis: patients with recurrent CDI}

An alternative analysis targeting patients who present with recurrent CDI was also performed. This patient population corresponds to the subgroup of patients in the two head-to-head clinical trials who, at baseline, presented with a first recurrent episode of CDI and were then randomly assigned to fidaxomicin or vancomycin (30) (treatment of the initial episode of CDI in these patients had consisted of metronidazole [52\%], vancomycin [18\%], combinations of these two [13.3\%] or no medication [17\%]) (30). In this subgroup of patients, the reported recurrence rates after successful initial treatment with fidaxomicin or 
TABLE 3

Model input parameters: Unit costs

\begin{tabular}{|c|c|c|}
\hline Parameter & Value (range in SA), \$ & References and assumptions \\
\hline \multicolumn{3}{|l|}{ Medication cost per day } \\
\hline Fidaxomicin & 220.00 & Common Drug Review report (27), 2012 \\
\hline \multicolumn{3}{|l|}{ Outpatient setting } \\
\hline Limited consultation with physician & 65.90 & Ontario Schedule for Physician Services, September 2011 (28), code A905 \\
\hline \multicolumn{3}{|l|}{ Inpatient setting } \\
\hline $\begin{array}{l}\text { Additional assessments by GE or ID } \\
\text { specialist }\end{array}$ & 58.80 & Codes C122-124 (28) \\
\hline Colectomy physician fees & 1,700 & Perras et al (26), 2011 \\
\hline \multirow{3}{*}{$\begin{array}{l}\text { Acute hospital stay for enterocolitis due } \\
\text { to Clostridium difficile infection (most } \\
\text { responsible diagnosis) }\end{array}$} & $12,192(9,113-15,050)$ & OCCI (29), 2009-2010, Acute Inpatient Database \\
\hline & & Base: All cases, CMG group 248-severe enteritis $(n=672)$ \\
\hline & & Low: Typical cases, CMG group 248-severe enteritis $(n=557)$ \\
\hline
\end{tabular}

CMG Case mix group; GE Gastroenterologist; ID Infectious diseases; OCCI Ontario Case Costing Initiative; SA Sensitivity analysis

\begin{tabular}{|c|c|c|c|}
\hline Parameter & Fidaxomicin & Vancomycin & Incremental outcome (fidaxomicin - vancomycin) \\
\hline Patients with initial cure, $n$ & 813 & 813 & 0 \\
\hline Patients with recurrence, $\mathrm{n}$ & 93 & 230 & -137 \\
\hline Patients hospitalized for recurrence, $\mathrm{n}$ & 18 & 44 & -26 \\
\hline Outpatient consultation & 23,856 & 23,856 & 0 \\
\hline Hospitalization (including physician fees) & $7,778,496$ & $7,778,496$ & 0 \\
\hline Subtotal & $10,242,846$ & $8,250,046$ & $1,992,800$ \\
\hline \multicolumn{4}{|l|}{ Economic - recurrence treatment, $\$$} \\
\hline Medication & 204,505 & 47,676 & 156,828 \\
\hline Total cost (initial + recurrence) & $10,677,167$ & $8,866,593$ & $1,810,574$ \\
\hline Incremental cost per recurrence avoided, $\$$ & & & 13,202 \\
\hline
\end{tabular}

vancomycin, thus, represent rates of second recurrence (30). The reported rates were not delineated by initial disease severity (30).

\section{Sensitivity analyses}

The impact of the uncertainty of model input parameters on the incremental cost per recurrence avoided was assessed using deterministic sensitivity analyses. The varied parameters were the recurrence rate after fidaxomicin treatment, the proportion of patients hospitalized for CDI recurrence, hospitalization costs, the number of additional in-hospital assessments by a specialist and medication treatment duration. Lower and upper limits of the 95\% CI of the weighted average of recurrence rates after fidaxomicin treatment from the two clinical trials were used as lower and higher bound values for the first sensitivity analysis. The lower bound value for the proportion of patients hospitalized for recurrence was the proportion of patients with complications during recurrence $(11 \%)$ as reported by Pépin et al (24). This value represents $-43 \%$ of the base case value. The higher bound value was $+43 \%$ of the base case value. The hospitalization cost was varied between the Ontario Case Costing Initiative cost for typical cases $(n=557)$ and the cost for all cases regardless of case mix group $(\mathrm{n}=711)$. The number of additional inhospital assessments by a specialist was varied between one and three. The medication treatment duration was varied by four days around the base case value (10 days), because clinical guidelines recommend up to 14 days of treatment $(14,15)$.

Analysis according to strain type

Because recurrence rates were significantly lower with fidaxomicin compared with vancomycin only for patients infected with non-NAP1/ B1/027 strains and not for patients with NAP1/B1/027 strains $(20,21)$, the impact of varying the proportion of patients infected with NAP1/ $\mathrm{B} 1 / 027$ was investigated by varying this proportion from $0 \%$ to $100 \%$ in a linear interpolation of averaged data from the two clinical trials.

Base case results

\section{RESULTS}

Compared with vancomycin, treatment of 1000 patients with severe CDI with fidaxomicin led to 137 fewer recurrences and 26 fewer patients hospitalized for recurrence (Table 4). The use of fidaxomicin increased the cost of initial treatment by $\$ 1.81$ million due to higher 
TABLE 5

Subgroup analysis results: Clinical and economic outcomes of fidaxomicin and vancomycin for the treatment of 1000 patients with first recurrent Clostridium difficile infection

\begin{tabular}{|c|c|c|c|}
\hline Parameter & Fidaxomicin & Vancomycin & Incremental outcome (fidaxomicin - vancomycin) \\
\hline \multicolumn{4}{|l|}{ Clinical, $n$} \\
\hline Patients with initial cure of first recurrence & 926 & 926 & 0 \\
\hline Patients experiencing second recurrence & 188 & 301 & -113 \\
\hline Patients hospitalized for recurrence & 36 & 58 & -22 \\
\hline \multicolumn{4}{|l|}{ Economic, \$ } \\
\hline Total cost of initial treatment of first recurrence & $10,242,846$ & $8,250,046$ & $1,992,800$ \\
\hline Total cost of second recurrence treatment & 876,192 & 806,329 & 69,863 \\
\hline Total cost (initial + recurrence) & $11,119,038$ & $9,056,376$ & $2,062,663$ \\
\hline Incremental cost per second recurrence avoided & & & 18,190 \\
\hline
\end{tabular}

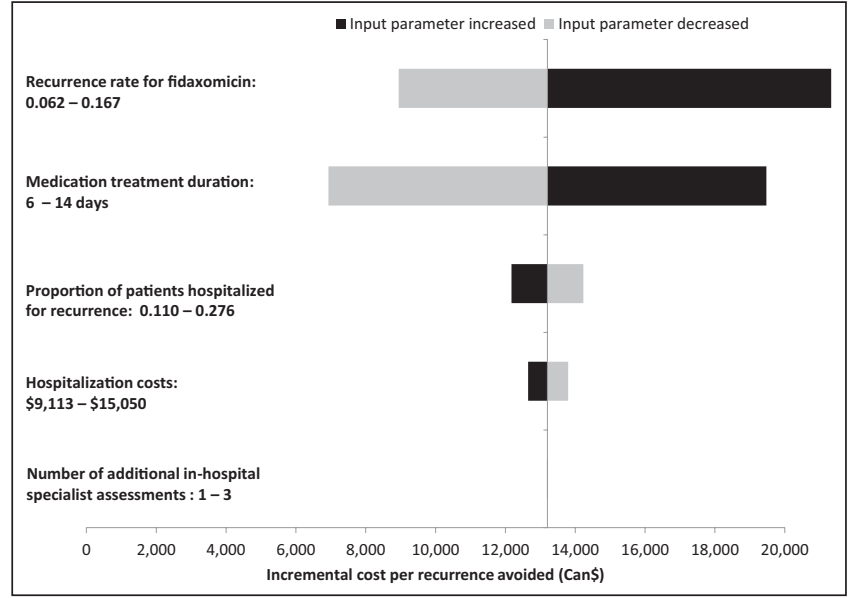

Figure 2) Deterministic sensitivity analyses of incremental cost of recurrence avoided by fidaxomicin versus vancomycin in 1000 patients with severe Clostridium difficile infection

cost of medication ( $\$ 2.40$ million) compared with vancomycin (\$0.25 million). Regarding the cost of the first recurrence, fidaxomicin resulted in overall savings $\$ 0.200$ million, mainly due to lower hospitalization costs in the fidaxomicin arm ( $\$ 0.225$ million versus $\$ 0.557$ million) partly offset by higher medication costs $(\$ 0.205$ million versus $\$ 0.048$ million). This resulted in a total incremental cost of $\$ 1.81$ million for fidaxomicin and an incremental cost of $\$ 13,202$ per recurrence avoided in the fidaxomicin arm.

\section{Subgroup analysis}

When only the subgroup of patients with recurrent CDI was taken into account, according to the pooled report of the two clinical studies (30), treatment of 1000 patients who experienced a first recurrence with fidaxomicin instead of vancomycin led to 113 fewer second recurrences and 22 fewer patients hospitalized for a second recurrence (Table 5). The initial incremental cost of treating 1000 patients with recurrent CDI with fidaxomicin rather than vancomycin was the same as in the base case ( $\$ 1.99$ million); the incremental cost of treating second recurrences was $\$ 69,863$ per 1000 patients. Collectively, this resulted in a total incremental cost for fidaxomicin versus vancomycin of $\$ 2.06$ million per 1000 patients with a first recurrence (had already experienced a CDI episode) or $\$ 18,190$ per second recurrence avoided. When only the costs of the initial treatment of the first recurrence were taken into account (ie, $\$ 1.99$ million per 1000 patients), disregarding treatment of second recurrences, the incremental cost per second recurrence avoided was $\$ 17,574$ (data not shown). If a first recurrent episode is treated with vancomycin and fidaxomycin is only reserved for a second recurrence, the total incremental cost of this strategy compared with continuing vancomycin treatment per 1000 patients with recurrent CDI would be reduced to $\$ 0.6$ million (data not shown).

\section{Sensitivity analyses}

The model was sensitive to the recurrence rate in the fidaxomicin arm. An increase of this parameter to the upper limit of its $95 \% \mathrm{CI}$ (ie, to 0.167 ) reduced recurrences avoided to 94 per 1000 patients initially treated with fidaxomicin versus vancomycin, while increasing the incremental total cost to $\$ 2.0$ million and the incremental total cost per recurrence avoided to $\$ 21,330$ ( $+62 \%$ from base case) . On the other hand, a decrease of the fidaxomicin recurrence rate to the lower limit of its $95 \%$ CI (ie, to 0.062 ) resulted in 180 recurrences avoided at an incremental total cost of $\$ 1.6$ million and $\$ 8,946$ per recurrence avoided ( $-32 \%$ of base case) (Figure 2$)$. The model was also sensitive to the duration of treatment; an extension from 10 to 14 days led to an increase of incremental cost per recurrence avoided by fidaxomicin compared with vancomycin to $\$ 19,472$ while a shorter treatment (six days) resulted in a decrease to $\$ 6,932$ (Figure 2$)$. The model was slightly sensitive $( \pm 8 \%)$ to variations in the proportion of patients hospitalized for recurrence, which was varied $\pm 43 \%$ around the base case value (Figure 2 ). The model was also slightly sensitive to variations in hospitalization costs, with an increase of incremental cost per recurrence avoided by fidaxomicin compared with vancomycin to $\$ 13,797$ ( $+5 \%)$ for the lower bound of costs, and a decrease to $\$ 12,650$ ( $-4 \%)$ for the higher bound. The model was marginally sensitive $( \pm 0.1 \%)$ to the number (one to three) of additional in-hospital assessments by a gastroenterologist or an infectious disease specialist.

Impact of the proportion of CDI cases caused by the NAP1/ B1/027 strain

When analyzing the combined clinical data according to strain type, recurrence rates between treatments showed a statistically significant difference for patients infected with non-NAP1/B1/027 strains (fidaxomicin: 0.097 versus vancomycin: $0.278 ; \mathrm{P}<0.0001$ ) but not for those infected with NAP1/B1/027 strains (fidaxomicin: 0.248 versus vancomycin: $0.282 ; \mathrm{P}=0.56$ ). Figure 3 shows the impact of the proportion of cases caused by the NAP1/B1/027 strain on the number of recurrent cases avoided by fidaxomicin versus vancomycin per 1000 patients entering the model (panel A), and the incremental cost per recurrence avoided (panel B) using weighted average recurrence rates from the two clinical trials $(20,21)$. In this figure, the solid lines show the results obtained using the mean estimates for all rates, whereas the dotted and dashed lines show the ranges obtained by varying the recurrence rate for fidaxomicin-treated patients infected with NAP1/B1/027 strains from lower and upper bounds, respectively, of its 95\% CI (ie, 0.168 to 0.327 [Table 1]).

If among 1000 CDI patients all cases were caused by non-NAP1/ B1/027 strains, 165 recurrences would be avoided with fidaxomicin versus vancomycin and the total incremental cost per recurrence avoided would reach a minimum of $\$ 10,504$. As the proportion of patients infected with NAP1/B1/027 strains increases, fidaxomicin becomes progressively less cost effective. If, among 1000 patients, all cases were caused by NAP1/B1/027 strains, the mean number of 


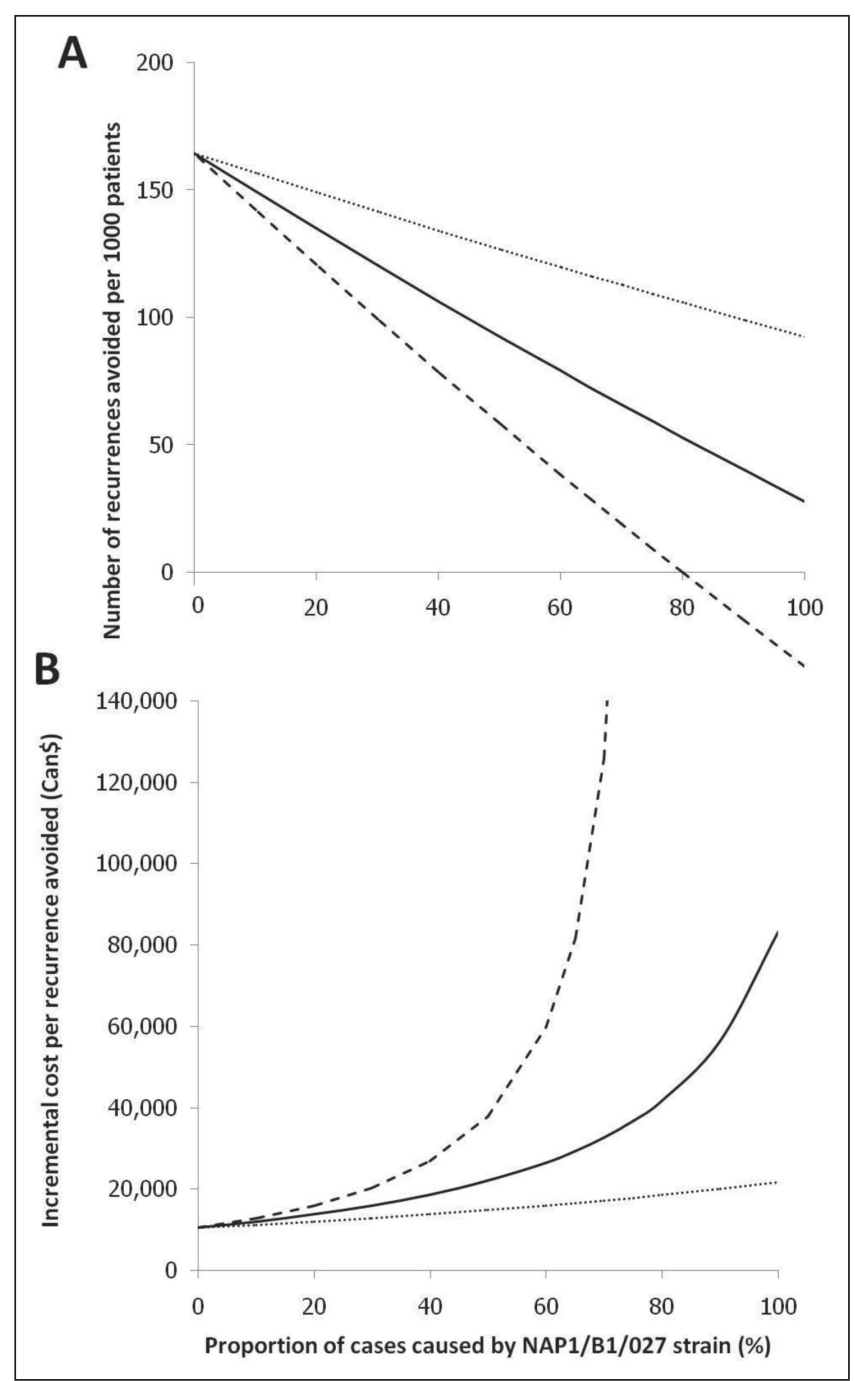

Figure 3) Relationship of number of recurrences avoided (A) and of cost per recurrence avoided (B) by fidaxomicin versus vancomycin with the proportion of cases caused by NAP1/B1/027 strains in 1000 patients with Clostridium difficile infection. Dotted and dashed lines show lower and upper bounds, respectively, of the 95\% CI for recurrence rate in fidaxomicin-treated patients infected with NAP1/B1/027 strains

recurrences avoided would reach a minimum of 28 and the mean incremental cost per recurrence avoided a maximum of $\$ 83,295$.

As the dotted and dashed lines show, the above-mentioned results were highly sensitive to the differential in recurrence rates among NAP1/B1/027-infected patients, with increasing uncertainty with a rising proportion of NAP1/B1/027-infected patients. In the case of a patient population with $100 \%$ of cases caused by NAP1/B1/027 strains, the number of recurrences avoided when using fidaxomicn versus vancomycin ranged between 93 and -37, and the corresponding incremental cost per recurrence avoided between $\$ 21,798$ and an additional cost of $\$ 71,151$ per additional case of recurrence. Similar results were obtained when varying the recurrence rate among NAP1/B1/027infected, vancomycin-treated patients across its 95\% CI, while keeping the corresponding fidaxomicin rate constant (data not shown).

\section{DISCUSSION}

In the past 15 years, CDI has become more challenging to the health care system due to increased incidence and severity. $\mathrm{C}$ difficile remains the most important cause of health care-associated diarrhea and can lead to severe outcomes including pseudomembranous colitis, toxic megacolon and death (2). Vancomycin is currently the treatment of choice for severe CDI $(14,15)$. Fidaxomicin, recently approved by Health Canada for the treatment of patients with CDI, was shown to be noninferior to vancomycin for clinical cure and was associated with significantly lower rates of recurrence overall and among the subpopulation of patients with CDI caused by non-NAP1/B1/027 strains $(20,21)$. For patients with severe CDI, the present study revealed an incremental cost of $\$ 13,202$ per recurrence case avoided by fidaxomicin compared with vancomycin from the perspective of the Canadian public health care system. Among patients presenting with a first recurrent episode of CDI, the incremental cost of a second recurrence avoided was $\$ 18,190$. The incremental cost-effectiveness ratio was sensitive to the duration of treatment, the recurrence rate and the proportion of CDI cases caused by the NAP1/B1/027 strain.

Although clinical guidelines for CDI in adults recommend 10 days of treatment, it is recognized that some patients may respond slowly to treatment and may require a longer course (eg, 14 days) (15). In addition, many clinicians prolong the treatment of CDI to avoid recurrence, especially in patients receiving other antimicrobial agents (15). In the present study, an increase in the duration of treatment from 10 days to 14 days led to a $47 \%$ increase (from $\$ 13,202$ to $\$ 19,472$ ) in the incremental cost per recurrence avoided by fidaxomicin compared with vancomycin.

Varying the recurrence rate among patients with severe CDI treated with fidaxomicin across its $95 \%$ CI, as derived from the two clinical studies, also strongly impacted model outputs, which, as a consequence, varied from $\$ 8,946$ to $\$ 21,330$ per recurrence case avoided.

In the analysis according to strain type, the proportion of CDI cases caused by the hypervirulent strain NAP1/B1/027 had a major impact on the comparative effectiveness and cost effectiveness of fidaxomicin versus vancomycin because, in contrast to non-NAP1/ B1/027 strains, fidaxomicin treatment did not lead to statistically significantly fewer recurrences in patients infected with the NAP1/ B1/027 strain $(20,21)$. The NAP1 strain is postulated to be more virulent than other strains because of a deletion in the $t c d C$ gene leading to increased toxin A and B production (31). An association between NAP1/B1/027 and severe clinical outcomes $(32,33)$ as well as higher risk of infection rather than colonization (34) in nonepidemic settings was observed in Canada but not in the United States (35) and England (5), suggesting the involvement of uninvestigated local factors. The proportion of patients infected with NAP1 strains appears to be quite variable in time and location. During the six-month period from November 2004 to April 2005, it was reported to range from 7\% in Manitoba and Saskatchewan to 76\% in Quebec, with an average of $31 \%$ across nine Canadian provinces (33). Across other Canadian studies $(4,31,32,36)$, the proportion of patients infected with NAP1 strains ranged from 26\% in Ontario in 2004 to 2006 (75\% of which belonged to the NAP1 ribotype 027 associated with outbreaks) (36) to $75 \%$ during the 2003 to 2004 outbreak in the Montreal area (4) The two most recent studies reported a NAP1 proportion of $63 \%$ across six hospitals in Quebec and Ontario in 2006 to 2007 (34) and 53\% during an outbreak in Ontario in 2008 to 2009 (8). Assuming that 53\% of cases in a patient population are caused by the NAP1/B1/027 strain (the lowest value reported in Canadian outbreaks), the model predicts 89 fewer recurrences per 1000 patients treated with fidaxomicin rather than vancomycin at an incremental cost of $\$ 23,258$ per recurrence avoided (an increase of $76 \%$ from the base case).

The results of the present study should be considered in light of several limitations. Due to unavailability of data regarding the risk of subsequent recurrent episodes and on outcomes of treatment of recurrent episodes with fidaxomicin versus vancomycin, the model took into account the first recurrent episode in patients with severe disease (base case) or the second recurrent episode (subgroup analysis) in the 28 days following treatment of the initial episode or the first recurrence of CDI, respectively. An initial CDI episode can be followed by several recurrent episodes $(37,38)$, which would reduce the incremental cost per patient with recurrent disease avoided. In addition, avoidance of such CDI recurrences should reduce the rate of person-to-person transmission, which was not captured by our model. 
Another limitation was that the proportion of patients hospitalized for a first recurrence in the model $(19.3 \%)$ was indirectly inferred from two observations: $62 \%$ of patients experiencing a first episode of CDI were hospitalized (for any reason) within 60 days of a first recurrence (24); and $31 \%$ of rehospitalized patients received a primary diagnosis of CDI (25). Although fidaxomicin treatment was shown to lead to fewer recurrences compared with vancomycin (20), sensitivity analyses around this value $( \pm 43 \%)$ had a minor impact on the incremental cost per recurrence avoided. Also, it was assumed in the model that the first recurrence was of same length and severity compared with the initial episode of CDI. However, in a study enrolling $>200$ patients experiencing recurrent $\mathrm{C}$ difficile-associated disease, the first recurrence compared with the initial episode was associated with a shorter duration of diarrhea and less severity of other clinical symptoms such as fever and abdominal pain (38). Thus, according to these observations, the cost of first recurrence may be lower than that of the initial episode, implying that the incremental cost per recurrence avoided with fidaxomicin versus vancomycin may be underestimated.

Uncertainty regarding the recurrence rate differential between fidaxomicin and vancomycin for patients with severe disease, the current target population for vancomycin treatment, and especially for patients infected with the hypervirulent NAP1/B1/027 strain, for whom no statistically significant difference was shown in both clinical trials, also limits the generalizability of the model results. It is important to realize that these recurrence rates were based on subpopulations of the two clinical trials: a total of 292 patients with severe disease and of 230 patients infected with the NAP1/B1/027 strain, who were not further delineated by disease severity. More clinical data, ideally involving

\section{REFERENCES}

1. Dubberke ER, Wertheimer AI. Review of current literature on the economic burden of Clostridium difficile infection. Infect Control Hosp Epidemiol 2009;30:57-66.

2. Bartlett JG. Narrative review: The new epidemic of Clostridium difficile-associated enteric disease. Ann Intern Med 2006;145:758-64.

3. Loo VG, Poirier L, Miller MA, et al. A predominantly clonal multiinstitutional outbreak of Clostridium difficile-associated diarrhea with high morbidity and mortality. N Engl J Med 2005;353:2442-9.

4. MacCannell DR, Louie TJ, Gregson DB, et al. Molecular analysis of Clostridium difficile PCR ribotype 027 isolates from Eastern and Western Canada. J Clin Microbiol 2006:44:2147-52.

5. Morgan OW, Rodrigues B, Elston T, et al. Clinical severity of Clostridium difficile PCR ribotype 027: A case-case study. PLoS One 2008;3:e1812.

6. Pepin J, Valiquette L, Cossette B. Mortality attributable to nosocomial Clostridium difficile-associated disease during an epidemic caused by a hypervirulent strain in Quebec. CMAJ 2005;173:1037-42.

7. Pepin J, Valiquette L, Gagnon S, Routhier S, Brazeau I. Outcomes of Clostridium difficile-associated disease treated with metronidazole or vancomycin before and after the emergence of NAP1/027. Am J Gastroenterol 2007;102:2781-8

8. Pillai DR, Longtin J, Low DE. Surveillance data on outbreaks of Clostridium difficile infection in Ontario, Canada, in 2008-2009. Clin Infect Dis 2010;50:1685-6.

9. Gravel D, Miller M, Simor A, et al. Health care-associated Clostridium difficile infection in adults admitted to acute care hospitals in Canada: A Canadian Nosocomial Infection Surveillance Program Study. Clin Infect Dis 2009;48:568-76.

10. Pepin J, Valiquette L, Alary ME, et al. Clostridium difficile-associated diarrhea in a region of Quebec from 1991 to 2003: A changing pattern of disease severity. CMAJ 2004;171:466-72.

11. Pepin J, Alary ME, Valiquette L, et al. Increasing risk of relapse after treatment of Clostridium difficile colitis in Quebec, Canada. Clin Infect Dis 2005:40:1591-7.

12. Ghantoji SS, Sail K, Lairson DR, DuPont HL, Garey KW. Economic healthcare costs of Clostridium difficile infection: A systematic review. J Hosp Infect 2010;74:309-18.

13. Miller MA, Hyland M, Ofner-Agostini M, Gourdeau M, Ishak M Morbidity, mortality, and healthcare burden of nosocomial Clostridium difficile-associated diarrhea in Canadian hospitals. Infect Control Hosp Epidemiol 2002;23:137-40.

14. Bauer MP, Kuijper EJ, van Dissel JT. European Society of Clinical Microbiology and Infectious Diseases (ESCMID): Treatment
Canadian patients with severe disease, would be needed to increase the precision of the recurrence rate estimates. Local data would be particularly important in light of the apparent impact of the strain type (NAP1/ B1/027 versus non-NAP1/B1/027) on the differential in recurrence rates between fidaxomycin and vancomycin and the importance of the NAP1/B1/027 strain in recent Canadian outbreaks. Also, more realworld data is needed to explore in more detail the health care resource implications of recurrent CDI and to identify which populations would benefit the most from the available treatment options.

\section{CONCLUSION}

The use of fidaxomicin compared with vancomycin is associated with a cost increase for the Canadian health care system. In patients with severe CDI as defined in clinical guidelines, the total incremental cost per recurrence avoided with fidaxomicin versus vancomycin $(\$ 13,202)$ is sensitive to the recurrence rate after fidaxomicin treatment and the duration of treatment. The proportion of cases caused by the NAP1/ B1/027 strain in patient populations with CDI also has a strong impact on the differential effectiveness and cost effectiveness of the two treatments.

ACKNOWLEDGEMENTS: The authors acknowledge Dr Jacques Pepin from the Department of Microbiology and Infectious Diseases at the University of Sherbrooke (Sherbrooke, Quebec) for his invaluable input in validating the model and providing expert insight. The authors do not have any conflicts of interest to declare. This study was partially funded by an unrestricted research grant from Merus Labs (Toronto, Ontario).

guidance document for Clostridium difficile infection (CDI). Clin Microbiol Infect 2009;15:1067-79.

15. Cohen SH, Gerding DN, Johnson S, et al. Clinical practice guidelines for Clostridium difficile infection in adults: 2010 update by the Society for Healthcare Epidemiology of America (SHEA) and the Infectious Diseases Society of America (IDSA). Infect Control Hosp Epidemiol 2010;31:431-55.

16. Surawicz CM, Brandt LJ, Binion DG, et al. Guidelines for diagnosis, treatment, and prevention of Clostridium difficile infections. Am J Gastroenterol 2013;108:478-98.

17. Barbut F, Richard A, Hamadi K, Chomette V, Burghoffer B, Petit JC. Epidemiology of recurrences or reinfections of Clostridium difficile-associated diarrhea. J Clin Microbiol 2000;38:2386-8.

18. Fekety R, McFarland LV, Surawicz CM, Greenberg RN, Elmer GW, Mulligan ME. Recurrent Clostridium difficile diarrhea: Characteristics of and risk factors for patients enrolled in a prospective, randomized, double-blinded trial. Clin Infect Dis 1997;24:324-33.

19. Drekonja DM, Butler M, Macdonald R, et al. Comparative effectiveness of Clostridium difficile treatments: A systematic review. Ann Intern Med 2011;155:839-47.

20. Louie TJ, Miller MA, Mullane KM, et al. Fidaxomicin versus vancomycin for Clostridium difficile infection. N Engl J Med 2011;364:422-31.

21. Cornely OA, Crook DW, Esposito R, et al. Fidaxomicin versus vancomycin for infection with Clostridium difficile in Europe, Canada, and the USA: A double-blind, non-inferiority, randomised controlled trial. Lancet Infect Dis 2012;12:281-9.

22. Crook DW, Walker AS, Kean Y, et al. Fidaxomicin versus vancomycin for Clostridium difficile infection: Meta-analysis of pivotal randomized controlled trials. Clin Infect Dis 2012;55(Suppl 2):S93-103.

23. Stranges PM, Hutton DW, Collins CD. Cost-effectiveness analysis evaluating fidaxomicin versus oral vancomycin for the treatment of Clostridium difficile infection in the United States. Value Health 2013;16:297-304.

24. Pepin J, Routhier S, Gagnon S, Brazeau I. Management and outcomes of a first recurrence of Clostridium difficile-associated disease in Quebec, Canada. Clin Infect Dis 2006;42:758-64.

25. O'Brien JA, Lahue BJ, Caro JJ, Davidson DM. The emerging infectious challenge of Clostridium difficile-associated disease in Massachusetts hospitals: Clinical and economic consequences. Infect Control Hosp Epidemiol 2007;28:1219-27.

26. Perras C, Tsakonas E, Ndegwa S. Vancomycin or metronidazole for treatment of Clostridium difficile infection: Clinical and economic analyses. Canadian Agency for Drugs and Technologies in Health 
2011. <http://cadth.ca/en/products/health-technology-assessment/ publication/2775> (Accessed January 23, 2012).

27. Canadian Drug Expert Committee. Final CDEC recommendation. Fidaxomicin (Dificid). Canadian Agency for Drugs and Technologies in Health 2012 December 21. <www.cadth.ca/media/ cdr/complete/cdr_complete_Dificid_December_21_12.pdf> (Accessed June 5, 2013).

28. Ontario Ministry of Health and Long-Term Care. Schedule of benefits for physician services. Consultations and visits. Ontario Ministry of Health and Long-Term Care. 2011. <www.health.gov. on.ca/english/providers/program/ohip/sob/physserv/physserv_mn. html> (Accessed February 17, 2012).

29. Ontario Case Costing Initiative. Ontario case costing initiative website. Ontario Case Costing Initiative. 2011. <www.occp.com/> (Accessed February 20, 2012).

30. Cornely OA, Miller MA, Louie TJ, Crook DW, Gorbach SL. Treatment of first recurrence of Clostridium difficile infection: Fidaxomicin versus vancomycin. Clin Infect Dis 2012;55(Suppl 2):S154-S161.

31. Warny M, Pepin J, Fang A, et al. Toxin production by an emerging strain of Clostridium difficile associated with outbreaks of severe disease in North America and Europe. Lancet 2005;366:1079-84.

32. Hubert B, Loo VG, Bourgault AM, et al. A portrait of the geographic dissemination of the Clostridium difficile North American pulsed-field type 1 strain and the epidemiology of C. difficileassociated disease in Quebec. Clin Infect Dis 2007;44:238-44.

33. Miller M, Gravel D, Mulvey M, et al. Health care-associated Clostridium difficile infection in Canada: Patient age and infecting strain type are highly predictive of severe outcome and mortality. Clin Infect Dis 2010;50:194-201.

34. Loo VG, Bourgault AM, Poirier L, et al. Host and pathogen factors for Clostridium difficile infection and colonization. N Engl J Med 2011;365:1693-703.

35. Cloud J, Noddin L, Pressman A, Hu M, Kelly C. Clostridium difficile strain NAP-1 is not associated with severe disease in a nonepidemic setting. Clin Gastroenterol Hepatol 2009;7:868-73.

36. Martin H, Willey B, Low DE, et al. Characterization of Clostridium difficile strains isolated from patients in Ontario, Canada, from 2004 to 2006. J Clin Microbiol 2008;46:2999-3004.

37. Johnson S. Recurrent Clostridium difficile infection: A review of risk factors, treatments, and outcomes. J Infect 2009;58:403-10.

38. McFarland LV, Surawicz CM, Rubin M, Fekety R, Elmer GW, Greenberg RN. Recurrent Clostridium difficile disease: Epidemiology and clinical characteristics. Infect Control Hosp Epidemiol 1999;20:43-50.

39. Régie de l'assurance maladie du Québec. Liste de médicaments assurés. Régie de l'assurance maladie du Québec 2013 June 3;1-459. <www.ramq.gouv.qc.ca/fr/regie/lois/liste_med.shtml> (Accessed June 13, 2013). 


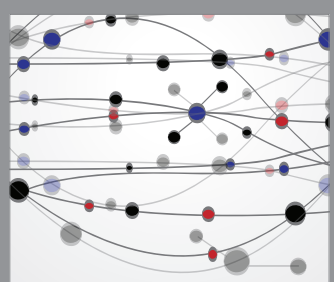

The Scientific World Journal
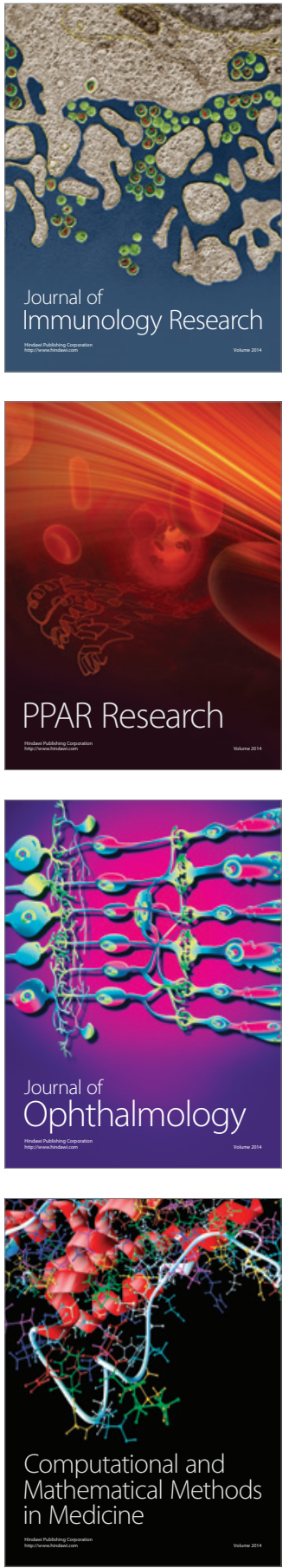

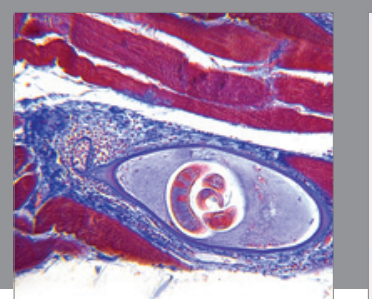

Gastroenterology Research and Practice

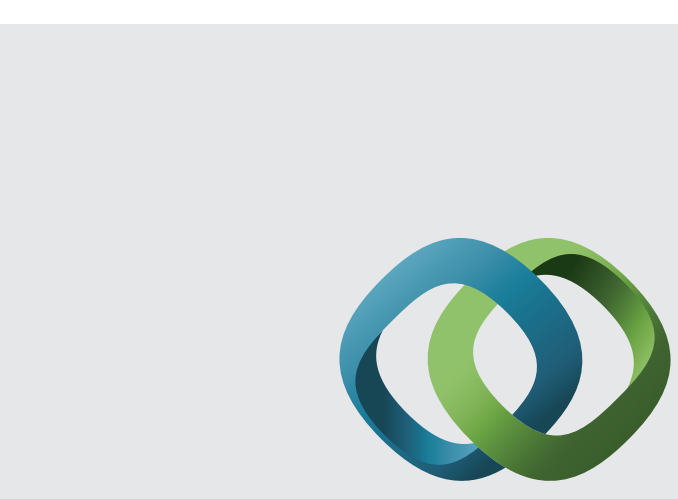

\section{Hindawi}

Submit your manuscripts at

http://www.hindawi.com
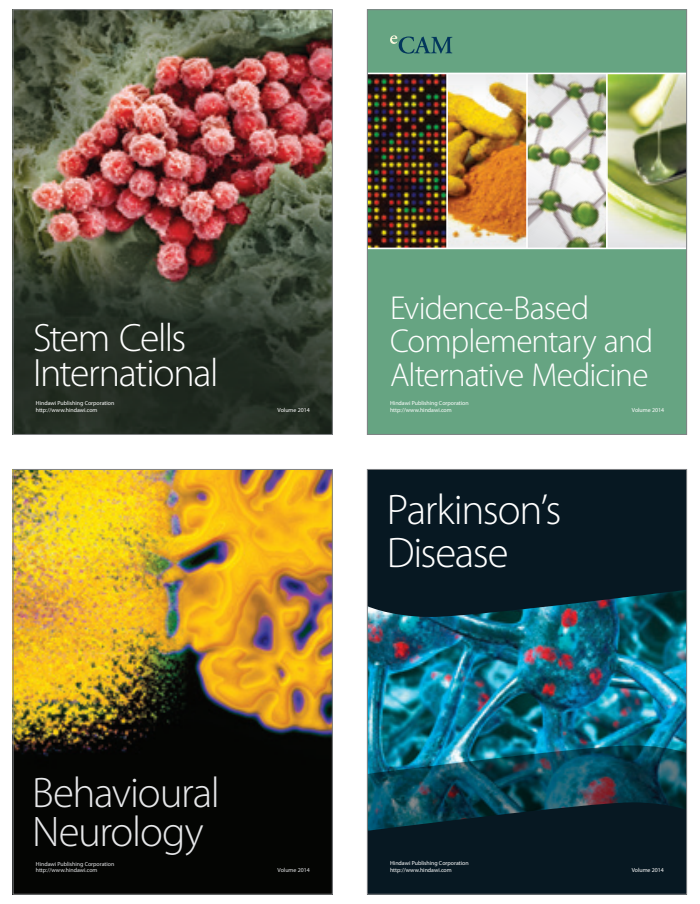
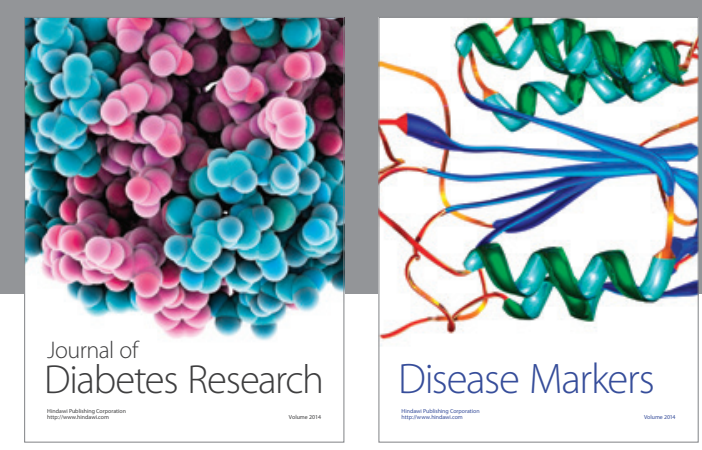

Disease Markers
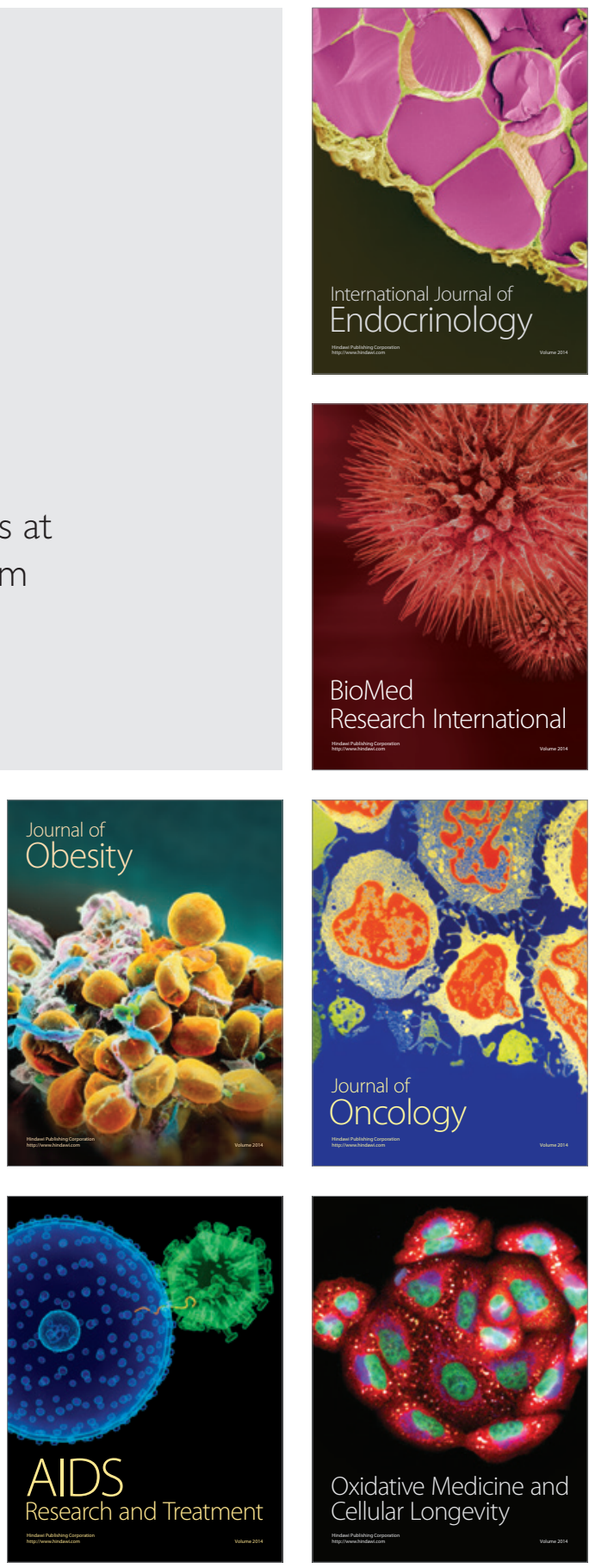